\title{
Nomenclature of Phosphorus-Containing Compounds of Biochemical Importance
}

(Recommendations 1976) $^{\mathrm{a}}$

IUPAC-IUB Commission on Biochemical Nomenclature ${ }^{\text {b }}$

The IUPAC Commissions on the Nomenclature of Inorganic and of Organic chemistry (CNIC and $\mathrm{CNOC}$ ) have recently provided, in the " $\mathrm{D}$ Rules"[1], recommendations for naming a large number of organic compounds containing phosphorus. Many such compounds are extremely important in biochemistry and hence in nearly all branches of biology and medicine. Most of the biochemically important ones are esters and/or anhydrides of various phosphorus-containing acids with complex organic alcohols and organic acids. Strict application of the "D-Rules"[1] to such compounds would result, in many cases, in rather complicated names, and these would be inconvenient for most biochemists and biologists to use.

However, other systems of nomenclature, in use in the biochemical literature, are available ${ }^{[2-5]}$. It is the purpose of this document to define and recommend certain of these for naming organic phosphorus-containing compounds in biochemical, biological, and medical publications.

A general summary and explanation of the principles involved in the nomenclature of biochemically important organic phosphorus compounds is given below. Representative compounds and their recommended names, together with those derived from more systematic nomenclature ${ }^{[6,7]}$, including names formed according to the "D-Rules"[1] where appropriate, are listed in the Tables.

1. Phosphoric esters, $\mathrm{RO}-\mathrm{PO}(\mathrm{OH})_{2}$, are named as $O$-substituted phosphoric acids or as substituted alcohols (Table I). Thus, choline $O$-(dihydrogen phosphate) and $O$-phosphonocholine are both appropriate names. The latter may be contracted to phosphocholine, but not changed to phosphorylcholine; "phosphoryl" is defined (ref. [1], Rule 5.66) as OP $<$ and requires, if used, the naming of all three groups attached to the phosphorus atom. However, "phosphoryl" is retained in derived terms such as the names of enzymes (e.g., phosphorylase) or of processes (e.g., phosphorylation).

Comment. The form $O$-phosphono-R stems from two considerations, (i) the definition (ref.[1], Rule 5.51) of phosphonic acid as $\mathrm{HPO}(\mathrm{OH})_{2}$, and

\footnotetext{
a Document of the IUPAC-IUB Commission on Biochemical Nomenclature (CBN), approved by IUPAC and IUB in 1976 and published by permission of the International Union of Pure and Applied Chemistry (IUPAC) and the International Union of Biochemistry (IUB). Comments and suggestions for future revisions of this document may be sent to any member of $\mathrm{CBN}^{\mathrm{b}}$. Reprints may be obtained from the NRC Office of Biochemical Nomenclature (W.E. Cohn, Director), Biology Division, Oak Ridge National Laboratory, P.O. Box Y, Oak Ridge, Tenn., U.S.A., 37830.

b Members of CBN are: O. Hoffmann-Ostenhof (Chairman), W.E. Cohn (Secretary), A.E. Braunstein, H. B.F. Dixon, B. L. Horecker, W. B. Jakoby, P. Karlson, W. Klyne, C. Liébecq, E. C. Webb.
} 
(ii) the principle in organic nomenclature of substitution of another atom or group for a hydrogen atom of a parent molecule, which, in this case, involves the replacement of the $\mathrm{H}$ of an $\mathrm{OH}$ group by $-\mathrm{PO}(\mathrm{OH})_{2}$, the phosphono group (ref.[1], Rule 5.52).

2. Phosphate may be used for "(dihydrogen phosphate)", "(disodium phosphate)", etc., (1) if the nature of the counter-ions is not known or is of no importance in the context, or (2) if a mixture of ionic forms (free acid and/or monoanion and/ or dianion) is in question. Thus, in most biochemical or biological systems, where the $\mathrm{pH}$ is around 7, "glucose phosphate" may be used in place of "glucose dihydrogen phosphate", the proper name for the protonated form.

\section{Comments}

(i) Although glucose phosphate is an ester, the term "phosphate ester" should not be used: "phosphoric ester" is the appropriate generic term.

(ii) When "phosphoric" is followed by a generic term (e.g., ester, amide, group), the word "acid" need not intervene. Hence "phosphoric ester" is complete and sufficient, and the residue transferred to glucose to form $O$-phosphonoglucose (see 1 above) is a "phosphoric residue".

(iii) To distinguish choline phosphate (ester) from choline phosphate (salt), the former could be written "choline $O$-phosphate". However, "phosphocholine" is unambiguous. (For $N$-phosphono compounds, see Section 6).

\section{Phosphoric anhydrides are of two types,}

(a) those in which two or more phosphoric residues are linked by oxygen atoms to yield diphosphates, triphosphates, etc. (e.g., ADP, ATP, etc; Table II) and (b) those in which phosphoric acid forms a "mixed anhydride" with a different type of acid (generally a carboxylic acid, e.g., acetic acid) (Table VI). The latter are named (ref.[1], Rule 5.64) as "R-ic phosphoric anhydrides" or as "R-yl phosphates" (e.g., acetic phosphoric anhydride or acetyl phosphate).

\section{Comments}

(i) "Pyro" should not be used for the substituted phosphoric anhydrides (ref. ${ }^{[6]}$, Rule 4.12) (Ta- ble II), but may be retained in such terms as inorganic pyrophosphate (ref.[6], Rule 5.213), pyrophosphatase, pyrophosphate-glycerol transferase, and pyrophosphorolysis ${ }^{[3]}$. (cf. Section 1 above re "phosphoryl").

(ii) The prefixes di, tri, tetra, etc. should not be used to indicate two or more independent phosphoric residues substituted on different oxygen (or other) atoms in a single compound; the appropriate multiplying prefixes for such compounds are bis, tris, tetrakis, etc. (ref. [1], Rule 5.51; ref.[6], Rules 2.251 and 4.12). For example, "fructose 1,6-diphosphate" could indicate a diphosphoric residue bridging positions 1 and 6 of fructose; the common biochemical substance is correctly named fructose 1,6 -bis(phosphate) (ref. ${ }^{[4]}$, Rule 4.4).

4. Phosphodiesters (Tables III and IV), which involve the bridging group - $\mathrm{PO}(\mathrm{OH})$-, could be named in terms of phosphinic acid, $\mathrm{H}_{2} \mathrm{PO}(\mathrm{OH})$, for which the prefix form is phosphinico[1]. However, the use of this prefix, as in ref. ${ }^{[3]}$, presents complications in placing the locants for unsymmetrical diesters. Hence, phosphinico is contracted to phospho, which is used as an infix between the names of the two alcohols. Thus, glycerophosphocholine is recommended ${ }^{[5]}$ for the well-known phospholipid component (previously ${ }^{[8]}$, but incorrectly, called glycerophosphorylcholine; cf. Section 1 above). This recommendation also illustrates the convention by which glycerol phosphate is contracted to glycerophosphate ${ }^{[5,8]}$, but this should not be done in a context where "glycero" may be confused with the residue of glyceric acid, as in glycerolactone, or with the prefix glycero used in Carbohydrate Nomenclature (ref. ${ }^{[2]}$, Rules Carb-8 and Carb-9). (For the placement of locants, see examples in Tables I and IV.)

\section{Comments}

(i) The use of "phosphoryl" in this situation requires an indication in the name that there is one hydroxyl group remaining on the phosphoric residue, and would thus further lengthen the name (see Section 1 above).

(ii) The diacyl derivatives of glycerophosphocholine are commonly expressed as derivatives 
of phosphatidic acid (Table IV), i.e., diacylglycerophosphocholine $\equiv$ phosphatidylcholine ${ }^{[5,8]}$.

(iii) The trivial names for the acid radicals of nucleotides (Table III) include the phosphoric residue, hence the latter is not specified in oligoor polynucleotide names, e.g., adenylylcytidine suffices for Ado-P-Cyd (locants omitted for clarity; cf.[9]).

(iv) The so-called cyclic phosphates (Table III), of which adenosine $3^{\prime}, 5^{\prime}$-phosphate* (cyclic AMP or (AMP) is the best-known example, are named in this form rather than in an inverted form, which would yield $3^{\prime}, 5^{\prime}$-phosphoadenosine. The word "cyclic", often added before "phosphate", is unnecessary if the locants are given.

(v) The infix "phospho" gives precedent for "diphospho", "triphospho", "tetraphospho", etc., for the doubly esterified oligophosphoric acids (Table II), e.g., uridinediphosphoglucose, adenosinediphosphoribose.

5. Nucleoside triphosphate analogues, in which a methylene group $\left(-\mathrm{CH}_{2}-\right)$, an imido group (-NH-), or a sulfur atom replaces an oxygen atom bridging two phosphorus atoms, could be named by an extension of the convention of inorganic nomenclature (ref. ${ }^{[6]}$, Rule 4.15) that employs $\mu$ to indicate a bridging group. Thus the compound symbolized as $\operatorname{Ado}\left(5^{\prime}\right) P\left[\mathrm{CH}_{2}\right] P P$ could be named adenosine $5^{\prime}-(1,2-\mu$-methylene $)$ triphosphate, and $\operatorname{Ado}\left(5^{\prime}\right) P P\left[\mathrm{CH}_{2}\right] P$ might be named adenosine $5^{\prime}-(2,3-\mu$-methylene)triphosphate. However, for the "methylene" part of these names, $[\alpha, \beta$-methylene $]$ and $[\beta, \gamma$-methylene $]$ are unambiguous, are consistent with the use of Greek letters as locants in other situations ${ }^{[7]}$, and are therefore recommended (see Table VIII). (The latter compound can be termed $5^{\prime}$-adenylyl methylenediphosphonate, but this name does not contain the significant term "triphosphate".)

\section{Comments}

(i) The use of square brackets here is similar to their use in amino-acid replacement ${ }^{[10]}$, indicating a replacement of the normal constituent.

\footnotetext{
* According to IUPAC Rules ${ }^{[7]}$ in analogous cases [e.g. hydrocarbon bridges (A-34.1), epoxy and other epi compounds (C-21 2.2, 514.4, 701.1, 815.2), lactones (C-472.1)] and common use by Chemical Abstracts, the comma between the locants is preferred to the colon recommended earlier by $\mathrm{CBN}^{[9]}$.
}

(ii) Although the bridging methylene group in the $\operatorname{Ado}\left(5^{\prime}\right) P P\left[\mathrm{CH}_{2}\right] P$ example should receive priority for numbering, i.e., should be $1,2-\mu$ methylene to accord with inorganic nomenclature (ref.[6], Rule 4.15), this would require an additional term (as in Table .VIII, column 2); it is therefore not suitable in this context, in which it is desirable to give adenosine first consideration (i.e., it is always considered to be linked to the $\alpha$ phosphorus atom).

(iii) A terminal substitution (e.g., sulfur replacing oxygen on $\mathrm{P}^{3}$ ) might be named adenosine $5^{\prime}$-[3-thio]triphosphate, but adenosine $5^{\prime}$-[ $\gamma$-thio $]$ triphosphate is recommended (see ii above).

(iv) The rules of inorganic nomenclature (ref. ${ }^{[6]}$, Table II) specify "imido" as the ligand name for -NH-; it is, in this case, an imide of phosphoric acid, hence "imido" is recommended for biochemical use with "triphosphate" or "diphosphate" (see Table VIII).

(v) The symbol for the nucleoside does not include the $5^{\prime}$-oxygen atom when the rest of the formula is written out in extenso. Thus $\operatorname{Ado}\left(5^{\prime}\right)$ $P\left[\mathrm{CH}_{2}\right] P \equiv \operatorname{Ado}\left(5^{\prime}\right)-\mathrm{O}-\mathrm{PO}(\mathrm{OH})-\mathrm{CH}_{2}-\mathrm{PO}_{3} \mathrm{H}_{2}$. Such extended representation may be useful for analogs such as $\mathrm{Ado}\left(5^{\prime}\right)-\mathrm{CH}_{2}-\mathrm{PO}_{3} \mathrm{H}_{2}$, a methylene analog of AMP, and Ado( $\left.5^{\prime}\right)-\mathrm{O}-\mathrm{PO}(\mathrm{OH})-\mathrm{CH}_{2}$ $\mathrm{AsO}_{3} \mathrm{H}_{2}$.

\section{Phosphoric amides (Table V) are named by} changing "acid" in the original acid name to "amide" (ref.[1], Rule 5.62). However, when the nitrogenous group supplying the amide moiety is known by a trivial name and that name is to be retained, the phosphoric amide may be named in the same manner as the esters (see Section 1 above), but not in the form in which "phosphate" is used as a suffix (see Section 2 above); e.g., phosphocreatine (for $N$-phosphonocreatine), but not "creatine phosphate", because "phosphate" means that all atoms attached to the phosphorus atom are oxygen atoms.

Comment. The contraction "phosphoamide" for phosphoric amide is often seen, but becomes unwieldy when either the amide or the phosphoric residue is substituted. Such compounds should be named as derivatives of phosphoramidic acid (or of a phosphoramidate), or of amidophosphoric acid (aminophosphate) [ref.[1], Rules $5.53(\mathrm{a}, \mathrm{b})$, $5.61(\mathrm{a}, \mathrm{b})]$. 
7. Fluorophosphoric acids, when doubly esterified, become fluorophosphates or phosphorofluoridates [ref.[1], Rules $5.53(\mathrm{a}, \mathrm{b}), 5.61(\mathrm{a}, \mathrm{b})$ ]. Thus the well-known compound $\left(\mathrm{Pr}^{\mathrm{i}} \mathrm{O}\right)_{2} \mathrm{PO}-\mathrm{F}$ or $\mathrm{iPr}_{2} P$-F ${ }^{[11]}$ may be called diisopropyl fluorophosphate or diisopropyl phosphorofluoridate (see Table VI).

\section{References}

1 IUPAC, "Nomenclature of Organic Chemistry, Section D", IUPAC Information Bulletin No. 31, Appendix on Tentative Nomenclature, August 1973, pp. $60-86$.

2 IUPAC-IUB, "Tentative Rules for Carbohydrate Nomenclature, Part 1, 1969", Biochem. J. 125, 673 - 695 (1971); Biochemistry 10, 3983 - 4004 (1971); Biochim. Biophys. Acta 244, 223 - 302 (1971); Eur. J. Biochem. 21, 455 - 477 (1971); J. Biol. Chem. 247, 613 - 635 (1972).

3 IUB, "Enzyme Nomenclature (1972)", Elsevier Publ. Co. Amsterdam-New York; Supplement 1: Biochim. Biophys. Acta 429, 1 - 45 (1976).

4 IUPAC-IUB, "Abbreviations and Symbols for Chemical Names of Special Interest in Biological Chemistry (1965 Tentative Rules)", J. Biol. Chem. 241, 527 - 533 (1966); Biochem. J. 101, 1 - 7 (1966); Biochemistry 5, 1445 - 1453 (1966); Eur. J. Biochem 1, 259 - 266 (1967); Hoppe-Seyler's Z. Phy. siol. Chem 348, 245 - 255 (1967); and elsewhere.

5 IUPAC-IUB, "Nomenclature of Lipids, Recommendations 1976", Hoppe-Seyler's Z. Physiol. Chem. 358, 617 - 631 (1977).

6 IUPAC, "Nomenclature of Inorganic Chemistry, Definitive Rules 1970", 2nd edit., Butterworths, London 1971.
7 IUPAC, "Nomenclature of Organic Chemistry, Definitive Rules for Sections A, B, C", 2nd edit., Butterworths, London 1971.

8 IUPAC-IUB, "Nomenclature of Lipids, (1967)", J. Biol. Chem. 242, 4845- 4849 (1967) and 245, 1511 (1970); Eur. J. Biochem. 2, 127 - 131 (1967) and 12, 1 (1970); Hoppe-Seyler's Z. Physiol. Chem. 350, 279 - 285 (1969); and elsewhere. Revision (1976) see ref. $[5]$.

9 IUPAC-IUB, "Abbreviations and Symbols for Nucleic Acids, Polynucleotides and their Constituents, Recommendations 1970", Arch. Biochem. Biophys. 145, 425 - 436 (1971); Biochem. J. 120, 449 - 454 (1970); Biochemistry 9, 4022 - 4027 (1970); Biochim. Biophys. Acta 247, 1 - 12 (1971); Eur. J. Biochem. 15, 203 - 208 (1970); Hoppe Seyler's Z. Physiol. Chem. 351, 1055 - 1063 (1970); J. Biol. Chem. 245, 5171 - 5176 (1970); Pure Appl. Chem. 40, 277 - 290 (1974); Mol. Biol (Moscow) 6, 167 - 178 (1972); and elsewhere.

10 IUPAC-IUB, "Rules for Naming Synthetic Modifications of Natural Peptides, Tentative Rules 1966 (amended 1972)", Biochemistry 6, 362 - 364 (1967); Eur. J. Biochem. 1, 379 - 381 (1967); Hoppe-Seyler's Z. Physiol. Chem. 348, 262 - 265 (1967); and elsewhere.

11 IUPAC-IUB, "Symbols for Amino-Acid Derivatives and Peptides, Recommendations 1971", Arch. Biochem. Biophys. 150, 1- 8 (1972); Biochem. J. 126, - 773 - 780 (1972); Biochemistry 11, 1726 - 1732 (1972); Biochim. Biophys. Acta 263, $205-212$ (1972); Eur. J. Biochem. 27, 201 - 207 (1972); J. Biol. Chem. 247, 977 - 983 (1972); Pure Appl. Chem 40, 315 - 331 (1974).

12 IUPAC-IUB, "Nomenclature of $\alpha$-Amino Acids, Recommendations 1974", Biochemistry 14, 449 - 462 (1975); Biochem. J. 149, 1 - 16 (1975); Eur. J. Biochem. 53, 1 - 14 (1975); and elsewhere. 


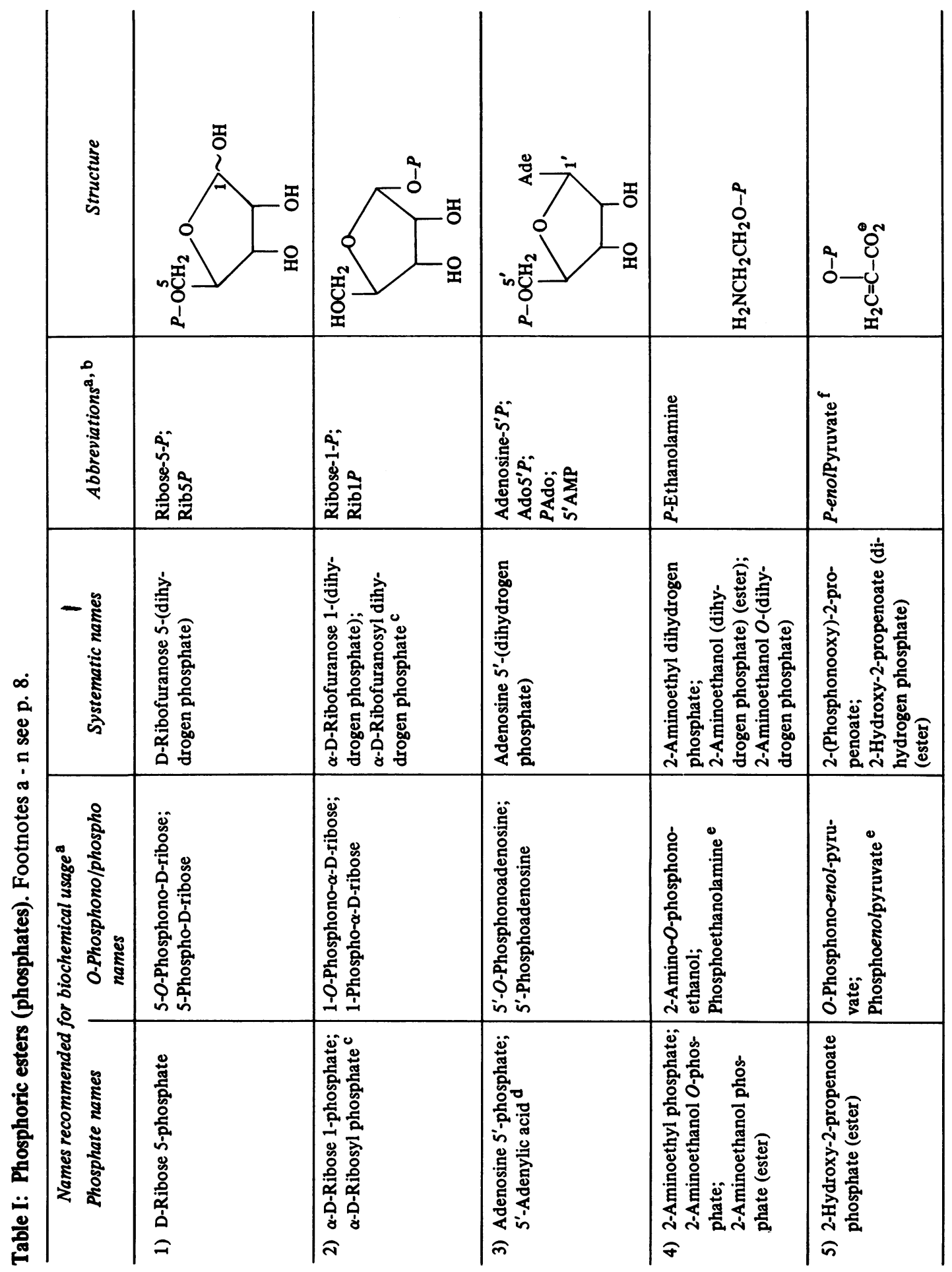

Vol. 171 


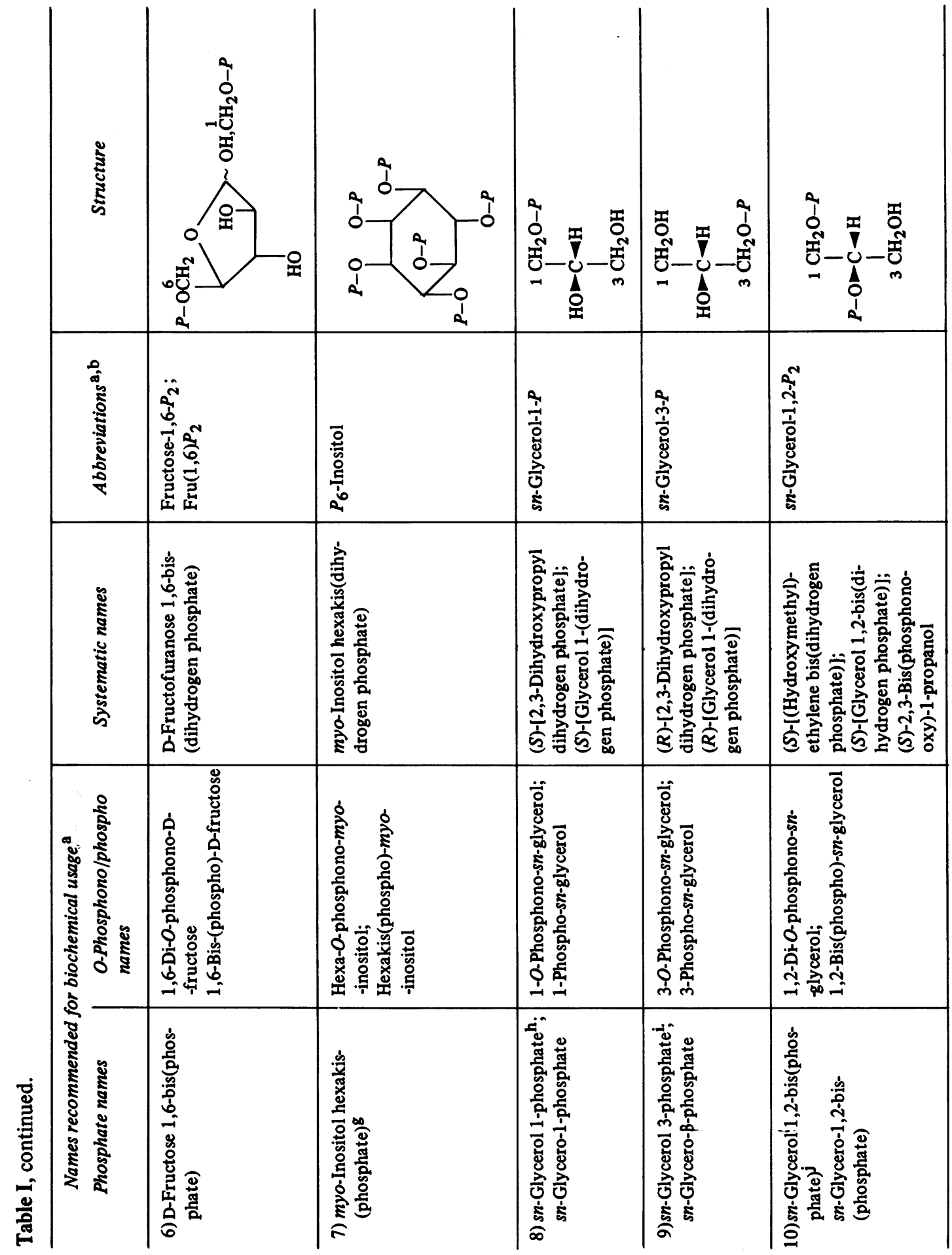




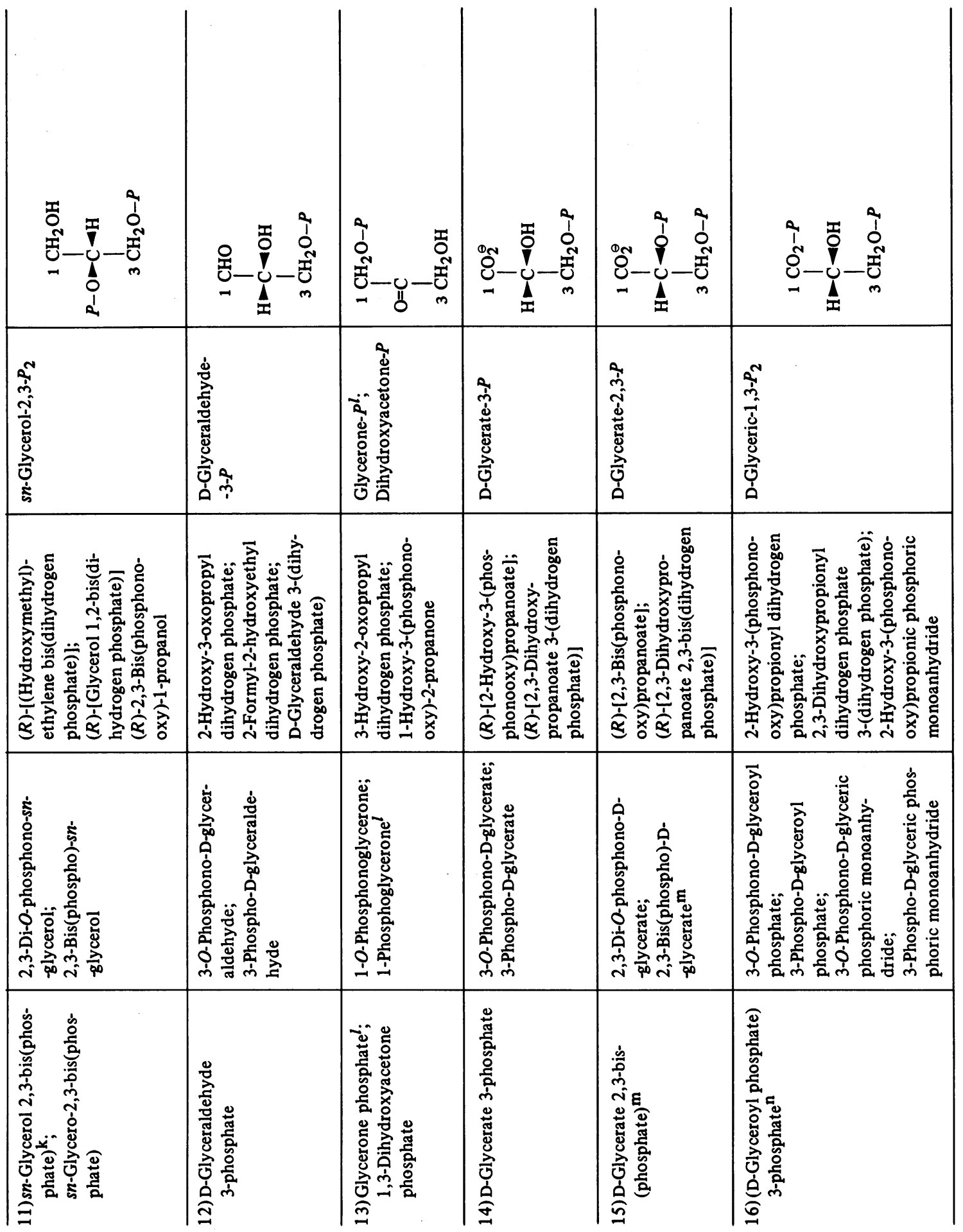

Vol. 171 


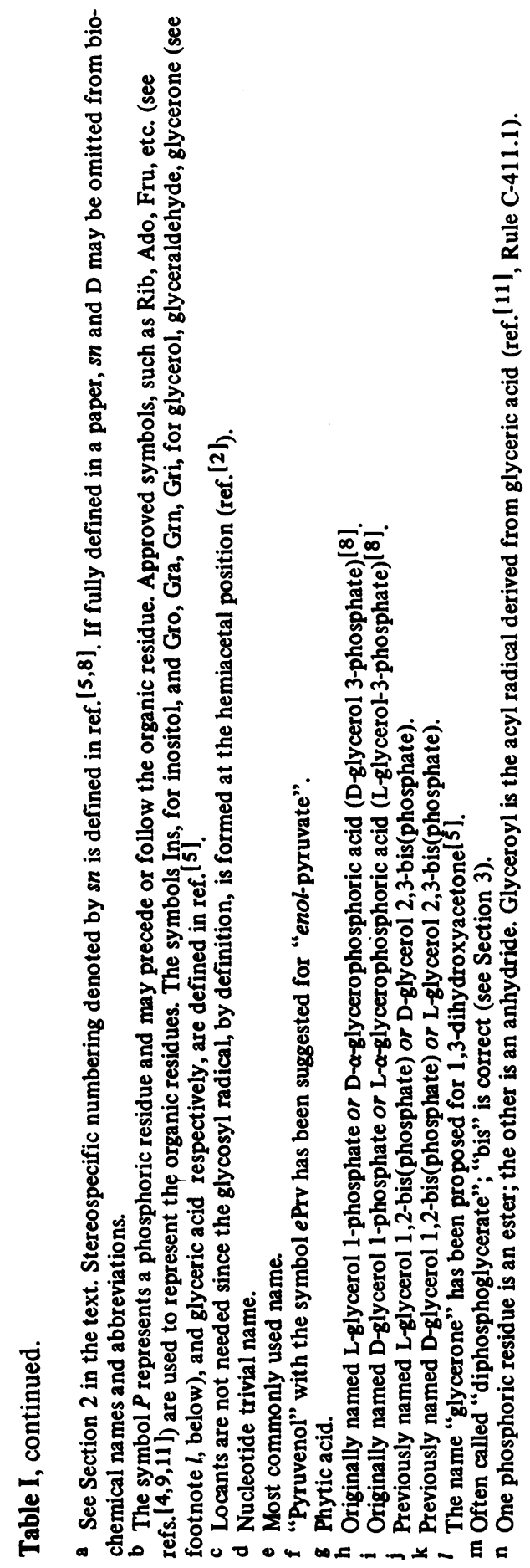




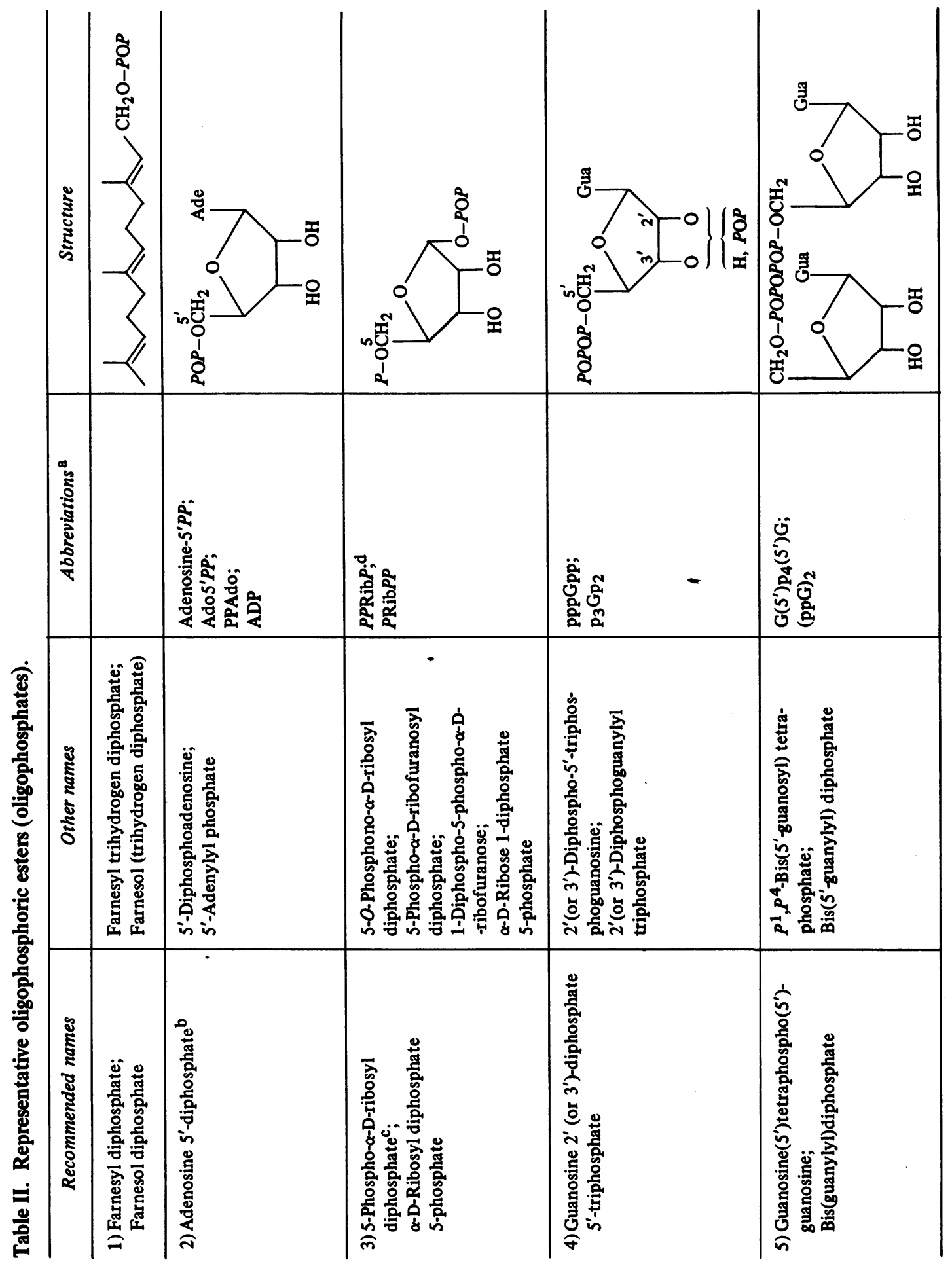

Vol. 171 


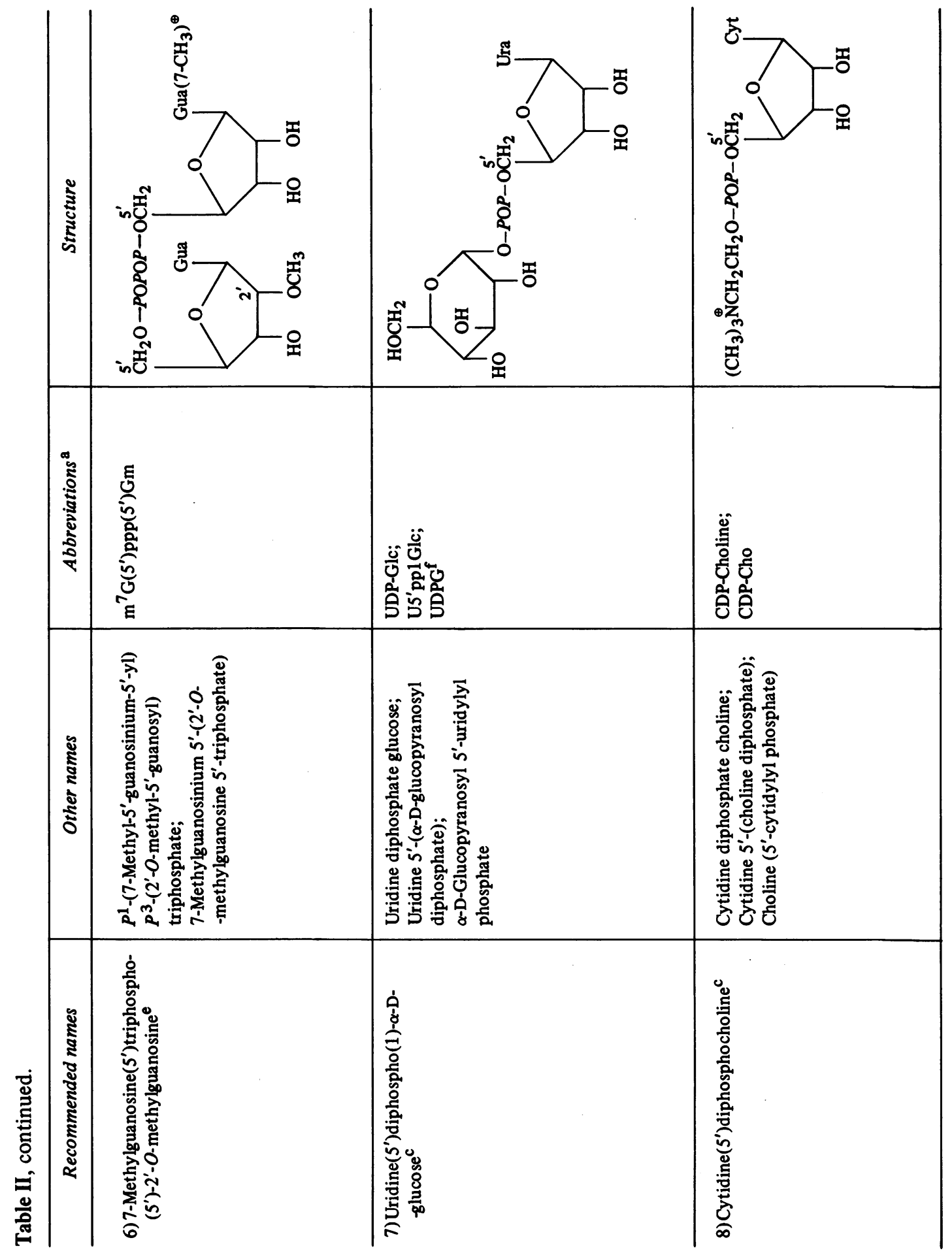




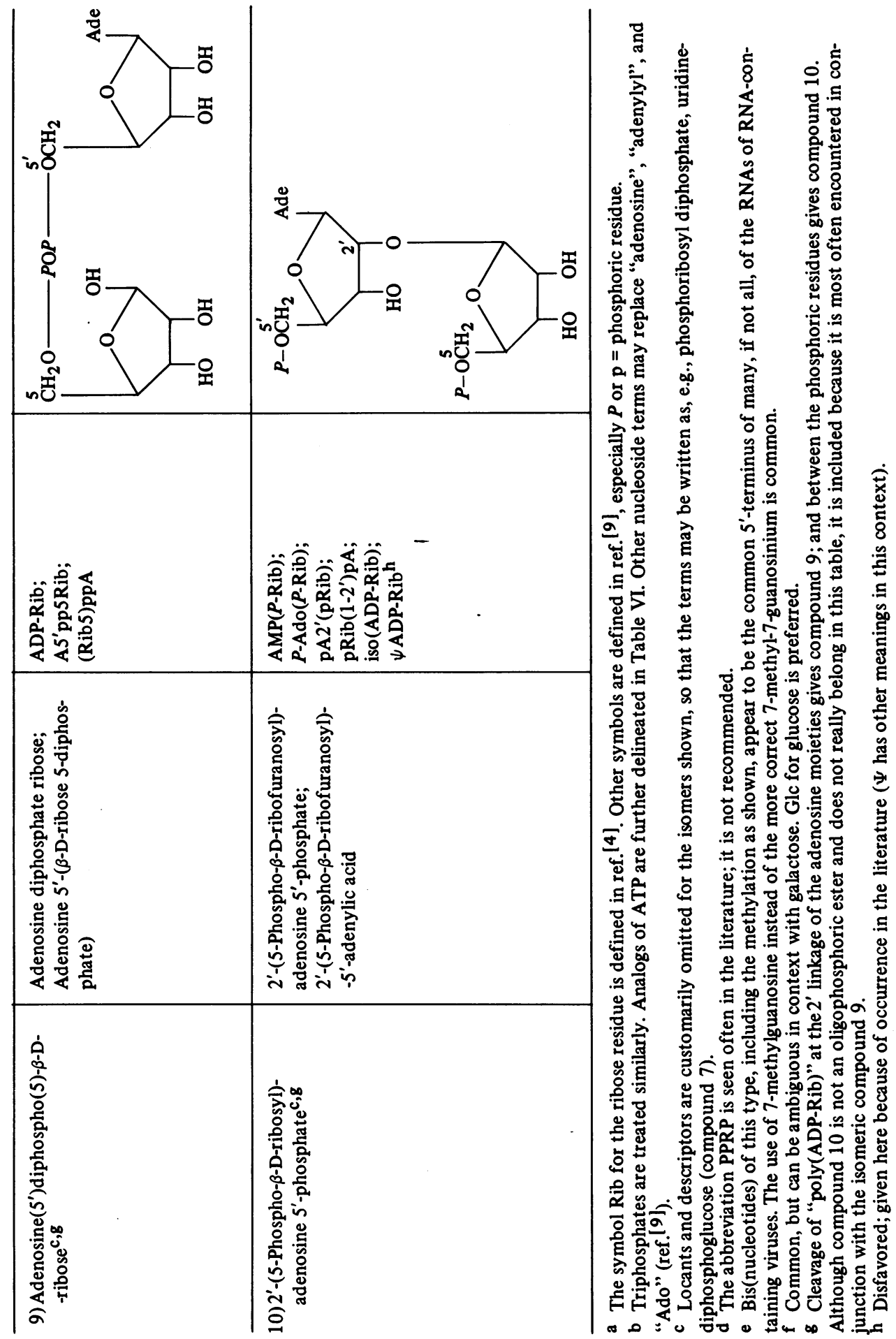

Vol. 171 

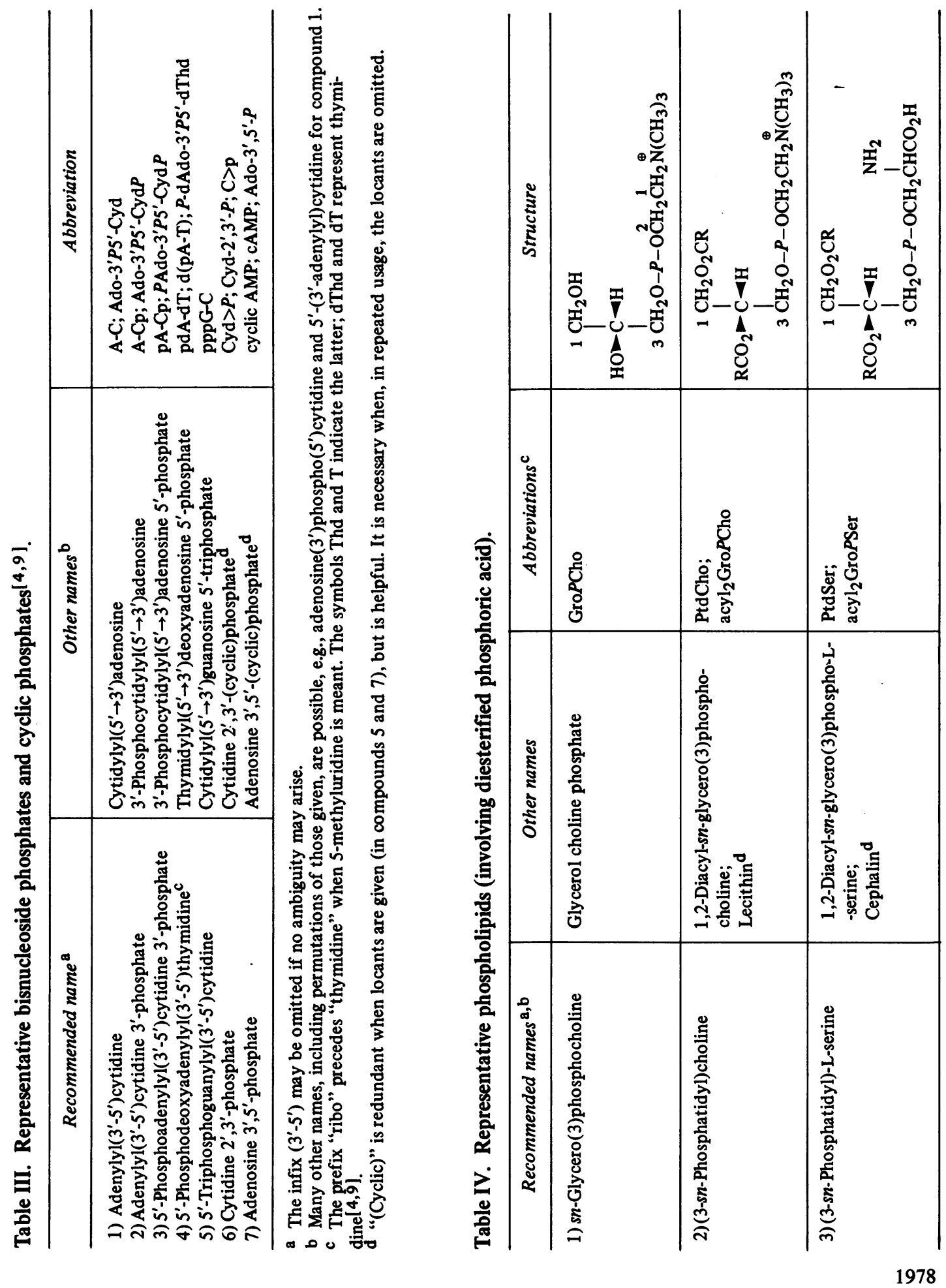


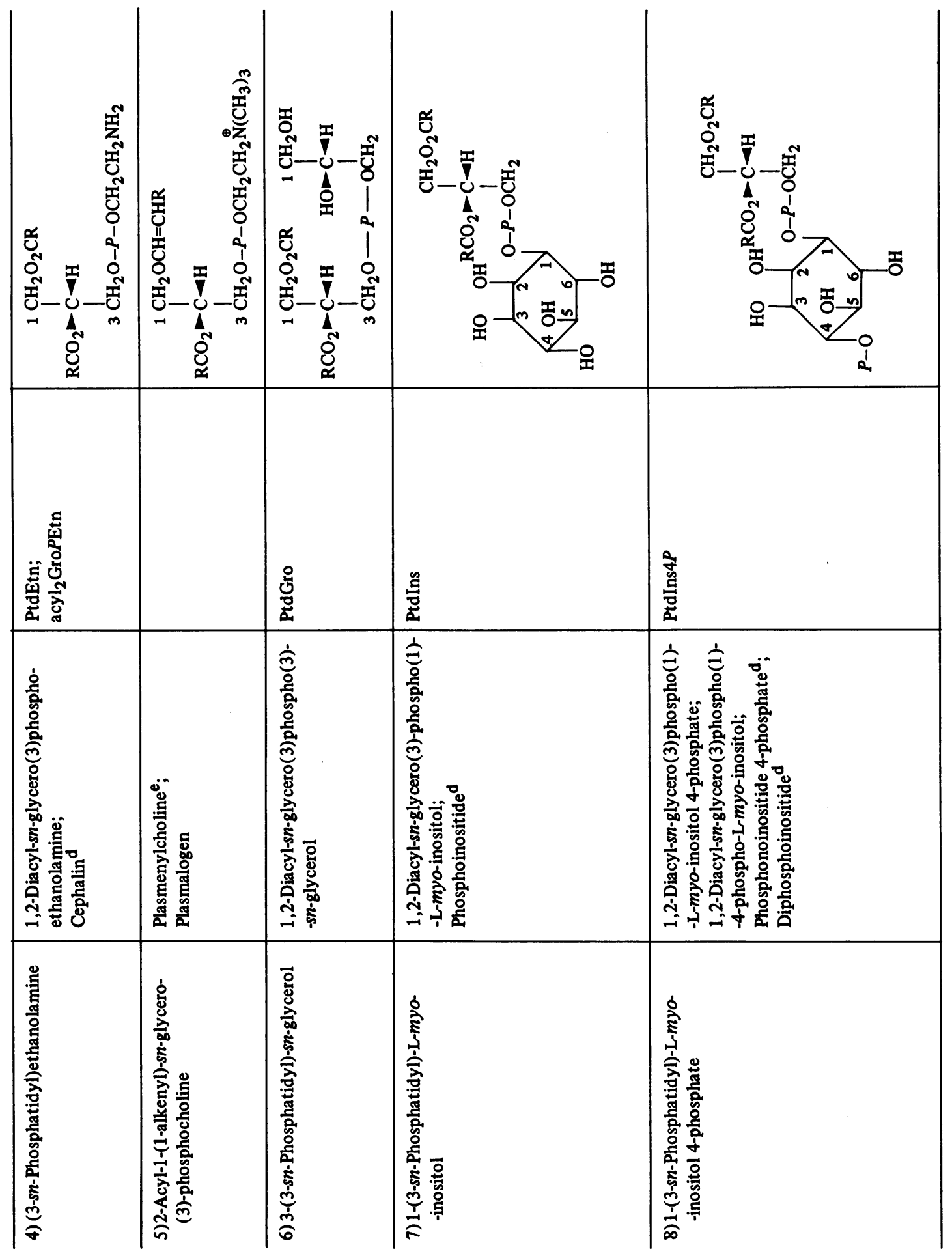

Vol. 171 


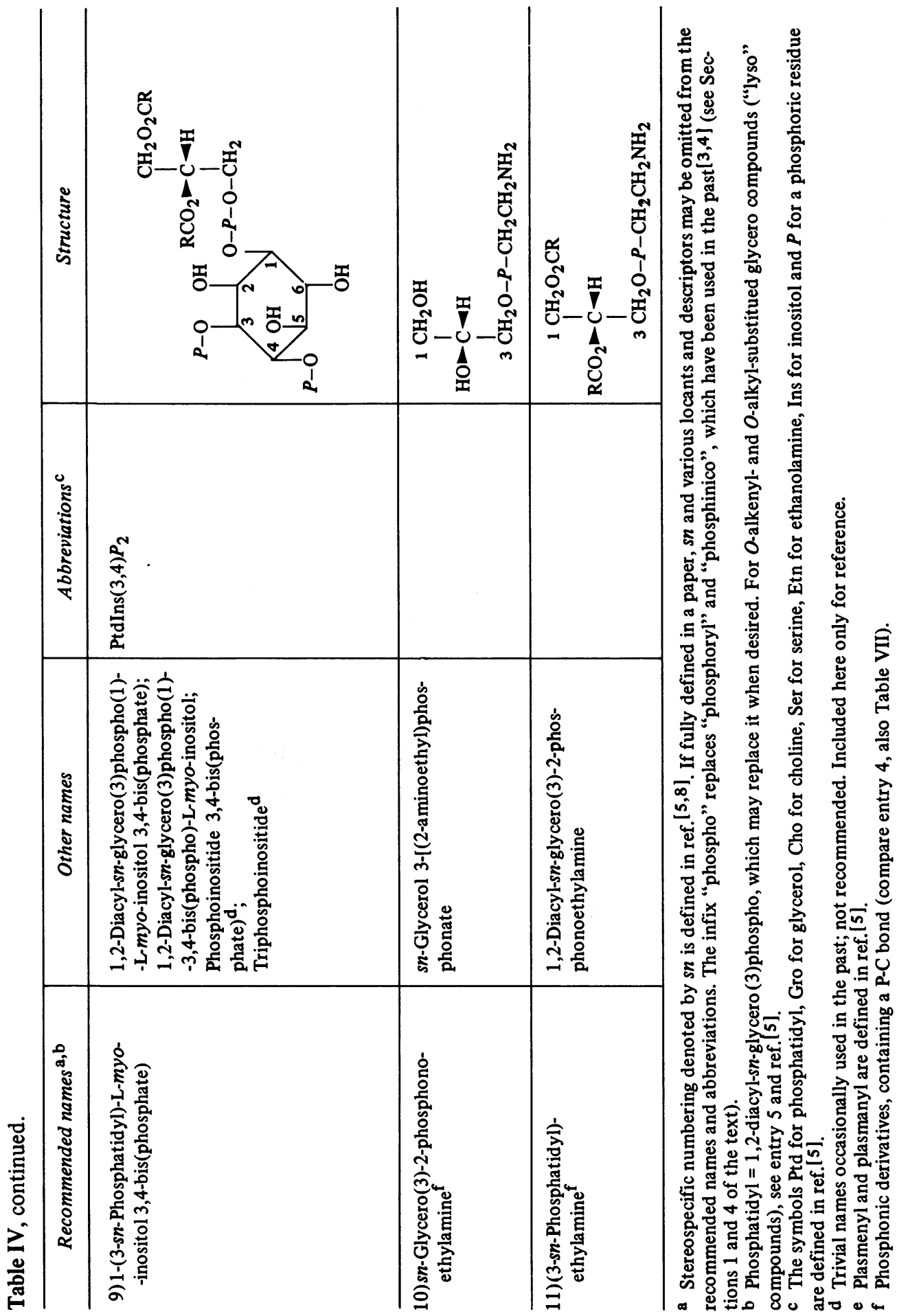




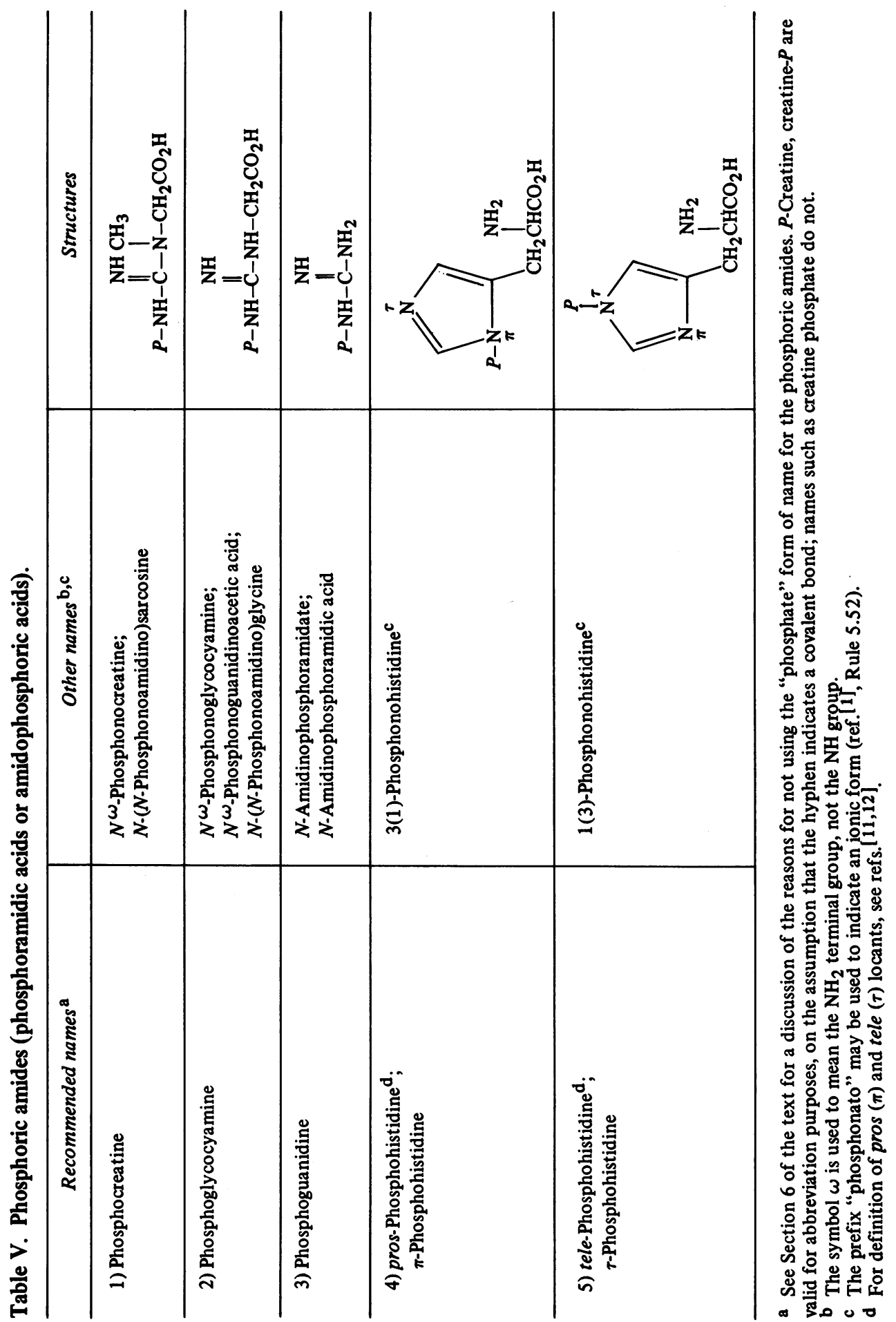

Vol. 171 


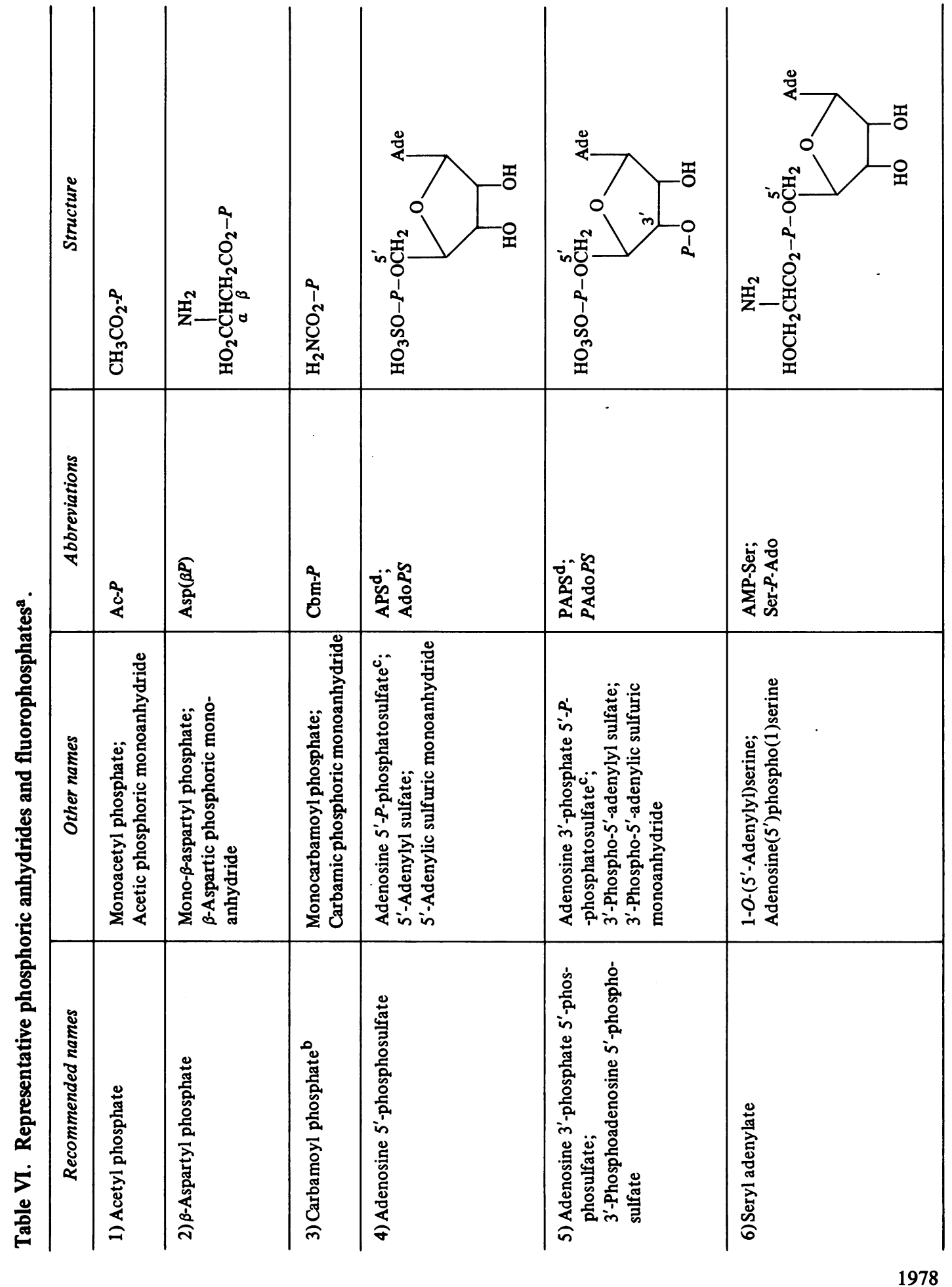



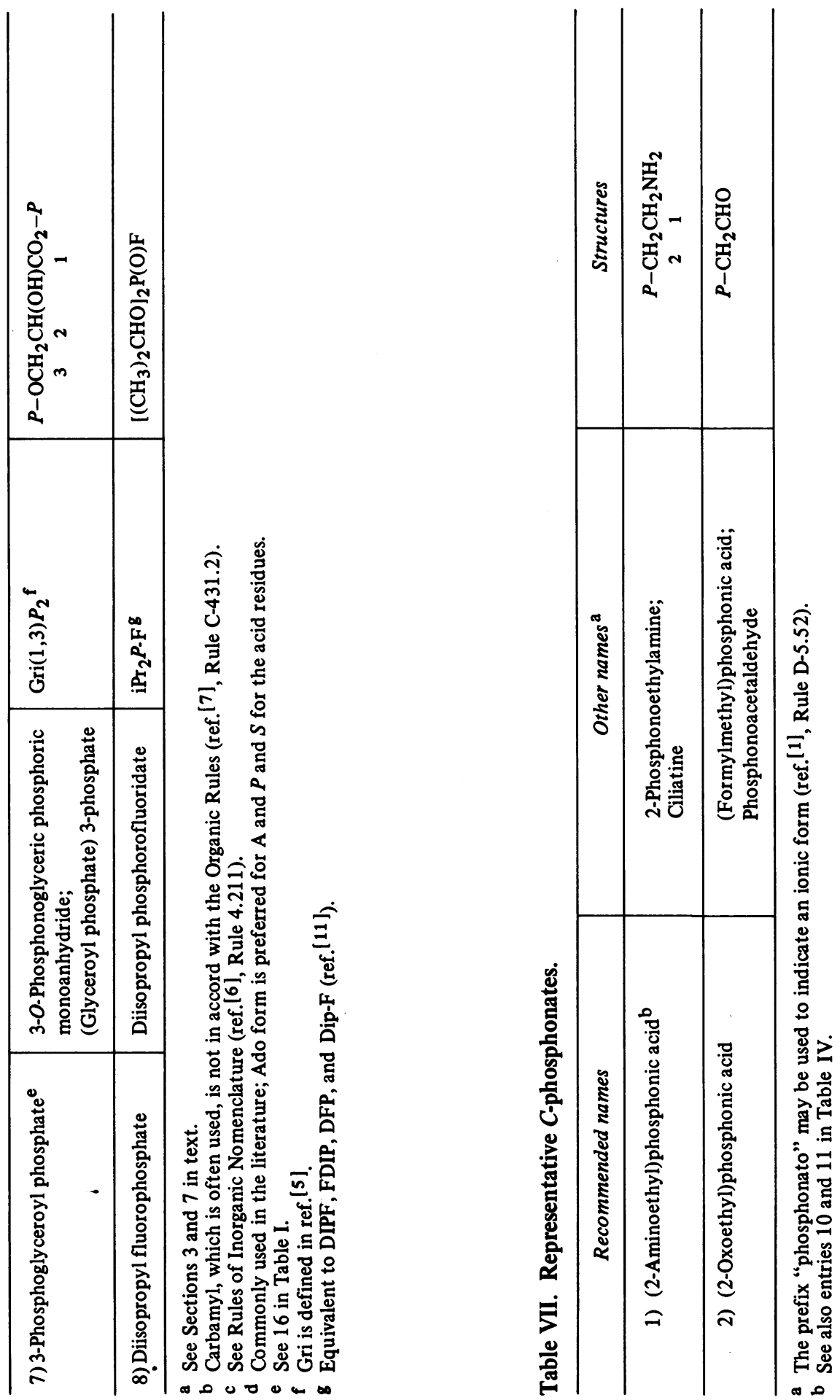

Vol. 171 


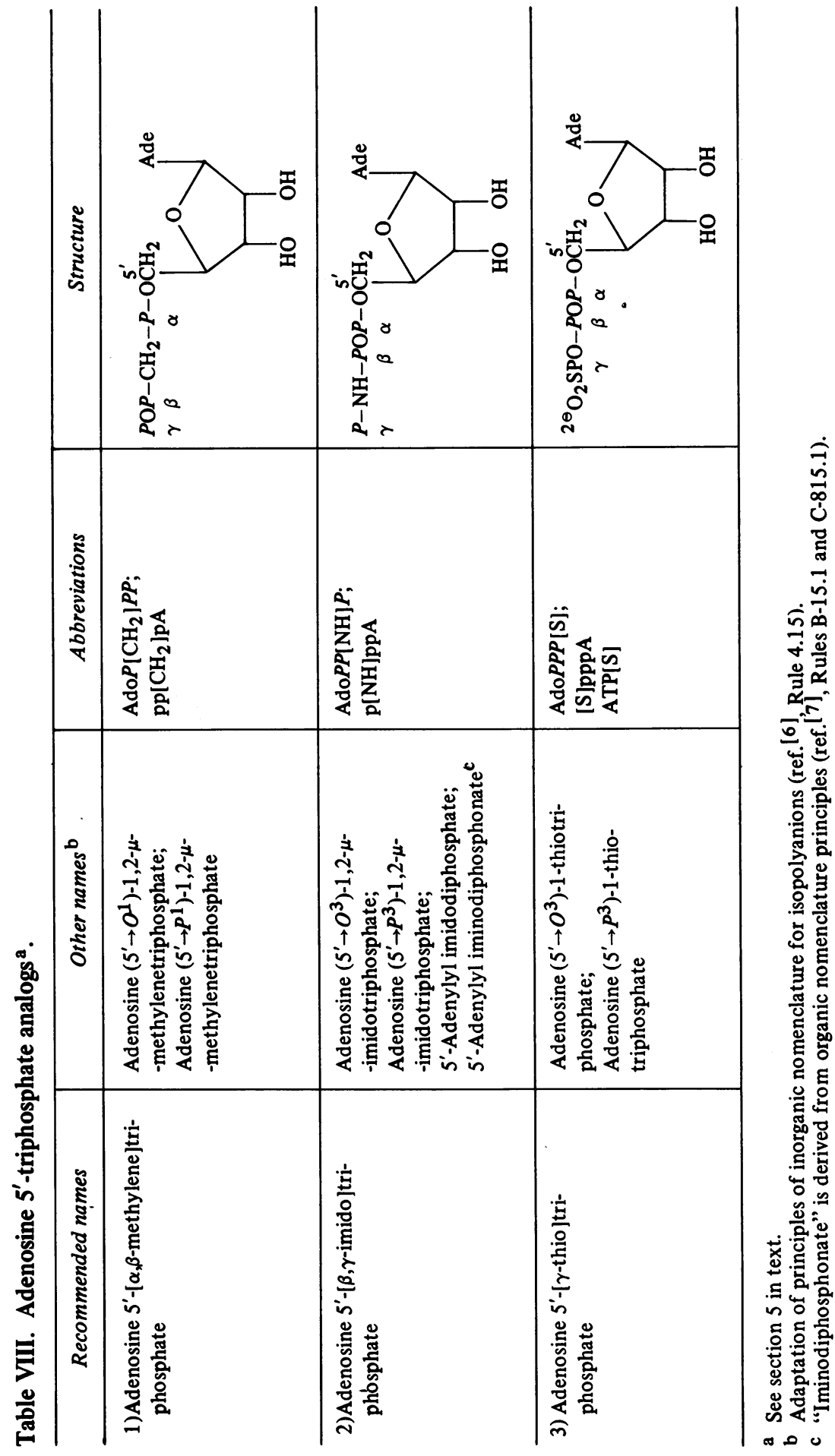




\section{CORRECTIONS}

(a) Table IV. The structures show the (naturally occurring) 1D isomers. Where appropriate, the names should have 1D in place of $\mathrm{L}$.

(b) Table IV, entry 9). The naturally occurring bisphosphate is 4,5 , not the 3,4 that is (correctly) depicted and named.

We are indebted to the Editors and Publishers of Hoppe-Seyler's Zeitschrift für Physiologische Chemie for permission to reproduce these Recommendations photographically.

Editorial note. These Recommendations are published as a service to the biochemical community. Publication does not imply endorsement of the Recommendations by the Biochemical Journal, but rather presents this information for consideration. 